\title{
Building's Refurbishment Computer Learning System with Augmented Reality
}

\author{
A. Kaklauskas, M. Kutinis, L. Kovachev, P. Petkov, I. Jackute, and L. Bartkiene
}

\begin{abstract}
Since 1999 Vilnius Gediminas Technical University has already introduced three e-learning Master's degree programmes. This paper proposes a way to integrate augmented reality and computer learning systems. In order to demonstrate the integration of the above systems in building refurbishment projects, the Building Refurbishment Computer Learning System with Augmented Reality (BR-CLS-AR) has been developed. The authors of this paper participated in the project "Learning Augmented Reality Global Environment" (LARGE), part of the Lifelong Learning Programme. One of LARGE's goals (on the part of Lithuania) was to integrate augmented reality and computer learning systems (i.e. to develop the BR-CLS-AR). To check the accuracy of the system, its entire solution process was reproduced manually. The results of the manual calculations matched those produced by the computer. Moreover, each individual phase in the system and its subsystems was checked with experts in this field, i.e. the underlying calculations were found to be in conformity with the experts' logical reasoning. Owing to the suggestions from these experts, some useful changes have been introduced in the system. The BR-CLS-AR consists of a computer learning subsystem and an augmented reality subsystem.
\end{abstract}

Index Terms-Augmented reality, building refurbishment, computer learning system, distance learning.

\section{INTRODUCTION}

Property Management, an e-learning Master's degree programme, was introduced at VGTU in 1999, followed by two more Master's degree programmes-Construction Economics in 2000, and Internet Technologies and Real Estate Business in 2003.

The authors of this paper participated in the project "Learning Augmented Reality Global Environment" (LARGE), part of the Lifelong Learning Programme. One of LARGE's goals (on the part of Lithuania) was to integrate augmented reality and computer learning systems (i.e. to develop the Building Refurbishment Computer Learning System with Augmented Reality, or BR-CLS-AR).

Smart growth, one of the priorities of the Europe 2020 Strategy, is driven by complex interactions between technical, social, economic, and human factors. The project Learning Augmented Reality Global Environment (LARGE) is designed to create a new type of learning environment that supports the educational/training institutions in delivering their curriculum in the most attractive and effective way for the learners. LARGE aims to build a global environment—based on this technology—-that will simplify

Manuscript received June 1, 2013; revised August 4, 2013.

A. Kaklauskas is with Vilnius Gediminas Technical University, Lithuania (e-mail: Arturas.Kaklauskas@vgtu.lt). the process of augmented reality content creation, allowing all educational/training institutions to benefit from its undoubted advantages. This Global Environment consists of a platform, serving as a basis for the system, and an integrated content development tool, which will allow the creation of appropriate educational/training AR content by the target groups. An AR system generates a composite view for the student which combines the real scene and the virtual scene generated by the computer that then augments the scene with additional information. The Learning Augmented Reality Global Environment superimposes graphics, audio, video, 3D objects and other enhancements from computer screens to real time environments expanding students' knowledge, skills and experience.

\section{BUILDING'S REFURBISHMENT COMPUTER LEARNING SYSTEM WITH AUGMENTED REALITY}

BR-CLS-AR consists of a Computer Learning Subsystem and an Augmented Reality Subsystem.

\section{A. Computer Learning Subsystem}

Computer Learning Subsystem consists of the Decision Support (BR-DSS), Knowledge and Device Subsystems. Below we shall briefly analyse these subsystems [1]-[4].

The BR-DSS allows students to: present information of the general physical and functional state of the building (see Fig. 1); present information of the physical state of the building's envelope; calculate the volume of work to be carried out; rationalize the energy consumption of the building; propose required measures to increase the quality of air and indoor environment and analyze the refurbishment scenarios by taking into account the system of criteria, etc. Students are advised to base their decisions on as much of their knowledge as possible. For example, goals, needs, available finances and existing explicit and implicit knowledge of all students (students, students, designers, manufacturers of construction materials, suppliers, contractors, facilities management organisations, financial institutions, municipalities, etc.) must be analysed thoroughly while developing possible alternatives for the building's refurbishment and making multiple criteria analysis of alternatives.

It is possible to create numerous alternatives for a building's refurbishment. At first, students are offered a system of criteria, on the basis of which building refurbishment specialists usually analyze the alternatives. On the basis of their needs and this system of criteria, students may devise their own system of criteria. Similarly, initial weights of criteria and values of qualitative indices are determined. Students receive typical weights of the criteria and values of the qualitative indicators describing the 
analyzed objects. On the basis of their experience and needs, students can then change the provided initial weights of the criteria and values of the qualitative indices. In such a case, each student receives a personalized decision support matrix adapted to his/her needs. The process of developing the system of criteria, determining the weight of the criteria and values of qualitative indices is open not only for one person but to a group of students (e.g. the student, students of a building, etc.) as well.

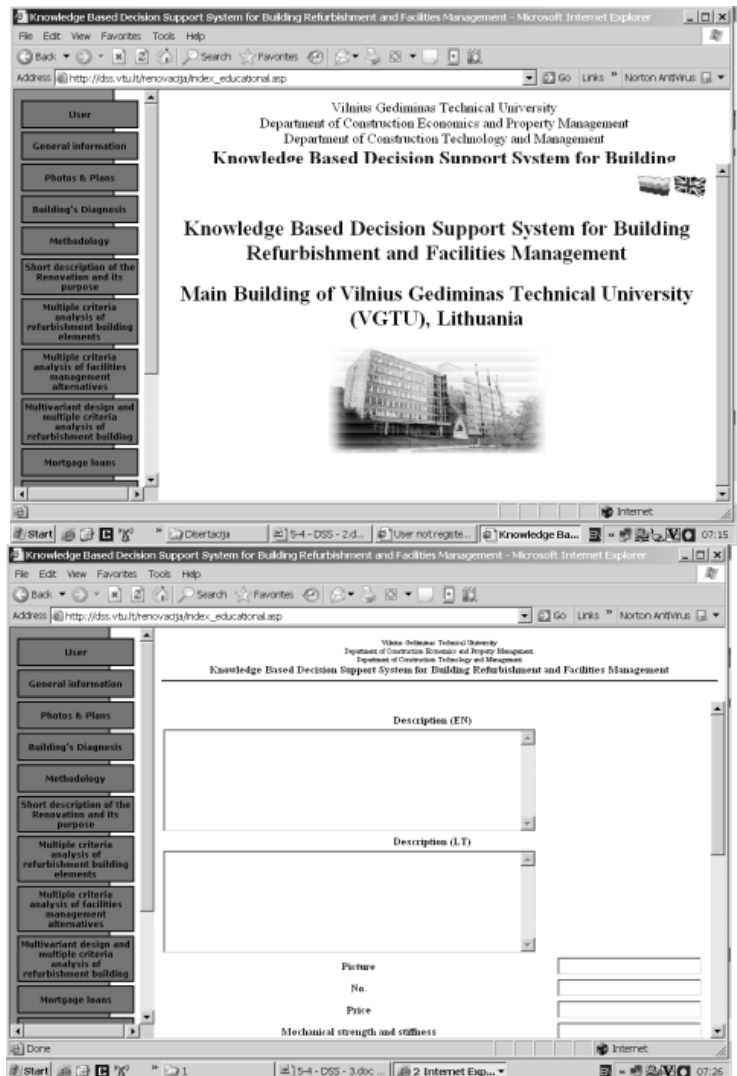

Fig. 1. Start-up screen of BR-CLS-AR (on the top) and screen to enter new information and knowledge (on the bottom).

The presentation of information and knowledge needed for decision-making in the BR-DSS may be in a tacit (digital/numerical, textual, graphical, diagrams, graphs and drawing, etc), photographic, sound, video) and in explicit forms. The presentation of explicit information involves criteria systems and subsystems, units of measurement, values and initial weight that fully define the provided variants. Tacit knowledge means a conceptual description of alternative solutions, the criteria and ways of determining their values and the weight, etc.

The following tables form the BR-DSS's database:

1) Initial data tables. These contain general facts about the building considered and information of its deterioration and obsolescence. Reasons for refurbishing and their significance as well as the money to be spent on it are also included [1].

2) Tables assessing refurbishment solutions (walls, windows (see Fig. 2), roof, floors, volumetric planning and engineering services, etc.). These contain explicit and tacit information and knowledge about alternative building refurbishment solutions relating to a building's enclosures, utilities and space planning, etc. [2]

3) Tables of multi-variant design. These provide explicit and tacit information and knowledge on the interconnection of elements to be renovated, their compatibility and possible combinations as well as data on the complex multi-variant design of a building's refurbishment.

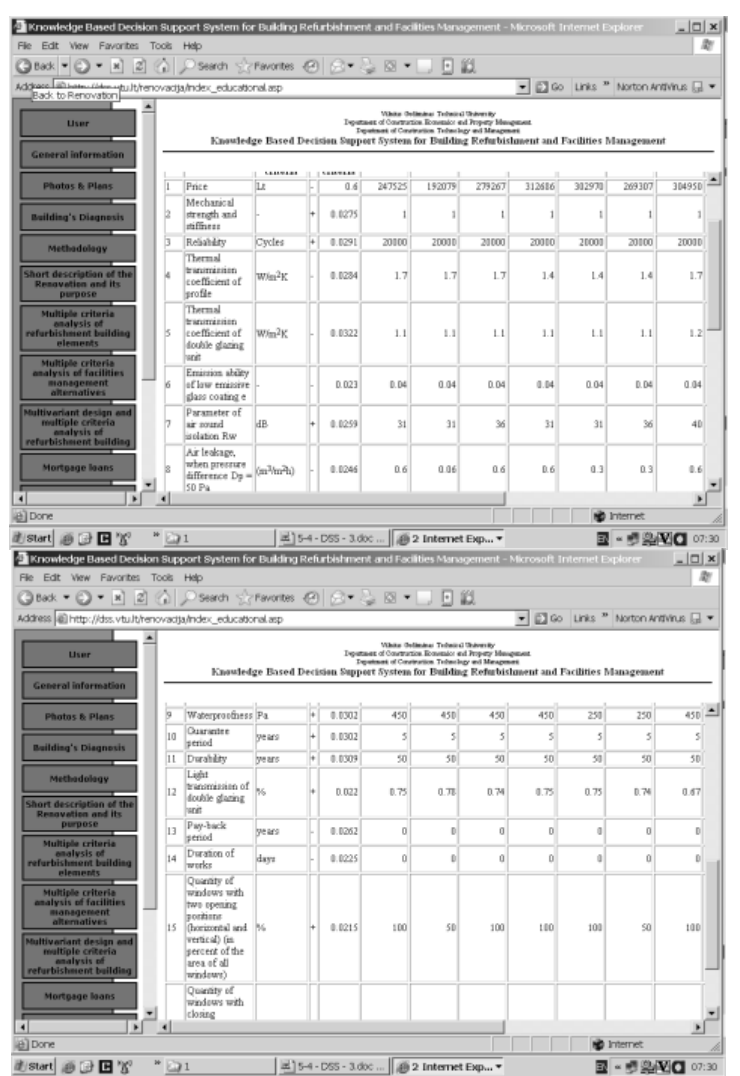

Fig. 2. A fragment of the table for evaluation of alternatives on windows' refurbishment

Data and knowledge can be arranged quite simply in the above-mentioned tables (Fig. 1 (on the bottom)).

In order to design and realize an effective building refurbishment project the available alternatives should be analyzed. A computer-aided multi-variant design requires the availability of tables containing data on the interconnection of the elements to be renovated and the solutions made. It also requires their compatibility, possible combination and the multi-variant design.

The efficiency of a building's refurbishment variant is often determined by taking many factors into account. These factors include an account of economic, aesthetic, technical, comfort, legal, social and other factors. The model-base of a decision support system (BR-DSS) should include models that enable a decision-maker to do a comprehensive analysis of the available variants and to make a proper choice.

Models have been developed with the help of methods multiple criteria project analysis [3], [4]: MEthod of complex Determination of the weIght of the CrIteria taking into account their quantitative and qualitative characteristics (MEDICI); Method of multiple criteria complex proportional evaluation of the projects (COPRAS); method of Defining the Utility degree and MArket value of a project (DUMA); MethOd of Multiple criteria Multivariant design of an Alternatives (MOMMA).

The more alternative versions that are investigated before making a final decision, the greater the possibility to achieve 
a more rational end result. Basing oneself on the collected information and the BR-DSS, it is possible to perform a multiple criteria analysis of the refurbishment project's components (walls, windows, roof, floors, volumetric planning and engineering services, etc.) and select the most efficient versions (see Fig. 3). After this, the received compatible and rational components of a refurbishment are joined into the projects. Having performed a multiple criteria analysis of the projects in this way, one can select the most efficient projects.

A model base allows the BR-DSS's student to select the most suitable refurbishment alternatives by comparing the measures that promote the greatest energy savings and increase a building's quality within budget constraints of the building's inhabitants. The following models of a model-base aim at performing the functions of: a model for developing alternative variants of a building's enclosures, a model for determining the initial weight of the criteria (using experts' methods), a model for the establishment of the criteria weight, a model for the multi-variant design of a building's refurbishment, a model for multiple criteria analysis and for setting priorities, a model for the determination of a project's utility degree and market value (see Fig. 4) and a model for negotiations.

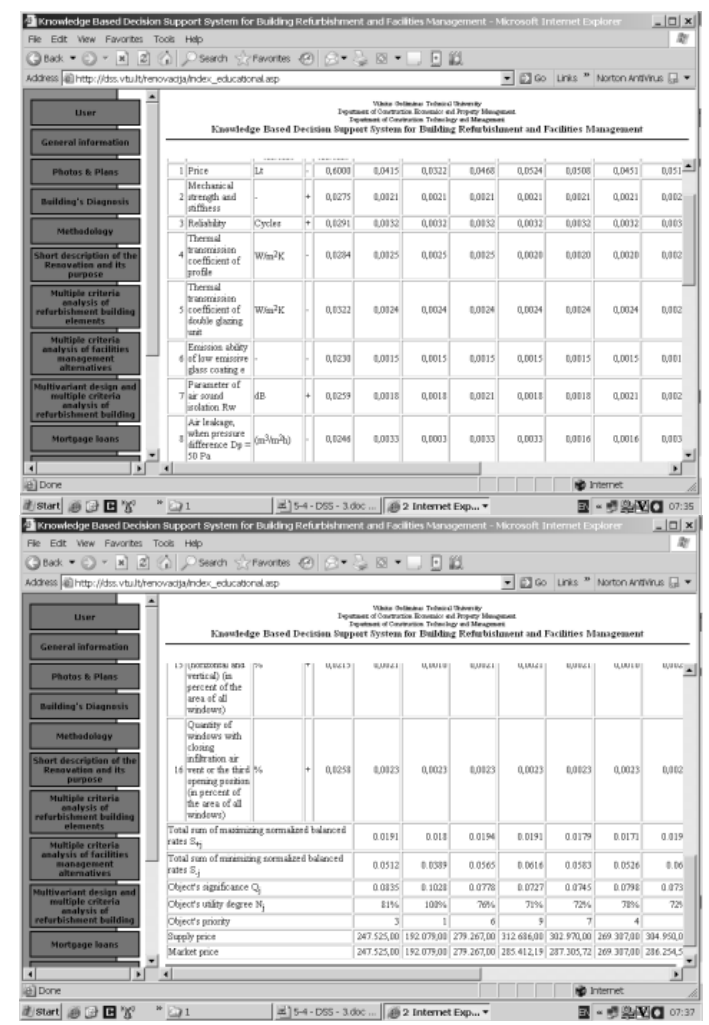

Fig. 3. A fragment of multiple criteria analysis of alternatives for windows refurbishment.

Based on the above models, the BR-DSS can make up to 100,000 building refurbishment alternative versions (see Fig. 5 ), perform their multiple criteria analysis, determine the utility degree, market value and select the most beneficial variant without human interference. The BR-DSS presents information about the building's diagnosis and questionnaires as well as different scenarios for the building's refurbishment. The report contains information about the estimation of potential energy savings and improvement of the quality of a building: thermal insulation of a building's envelope (walls, roof, and windows); potential impact of refurbishment to increase the quality of a building to the level of present standards. This is useful software for the selection best possible scenarios.

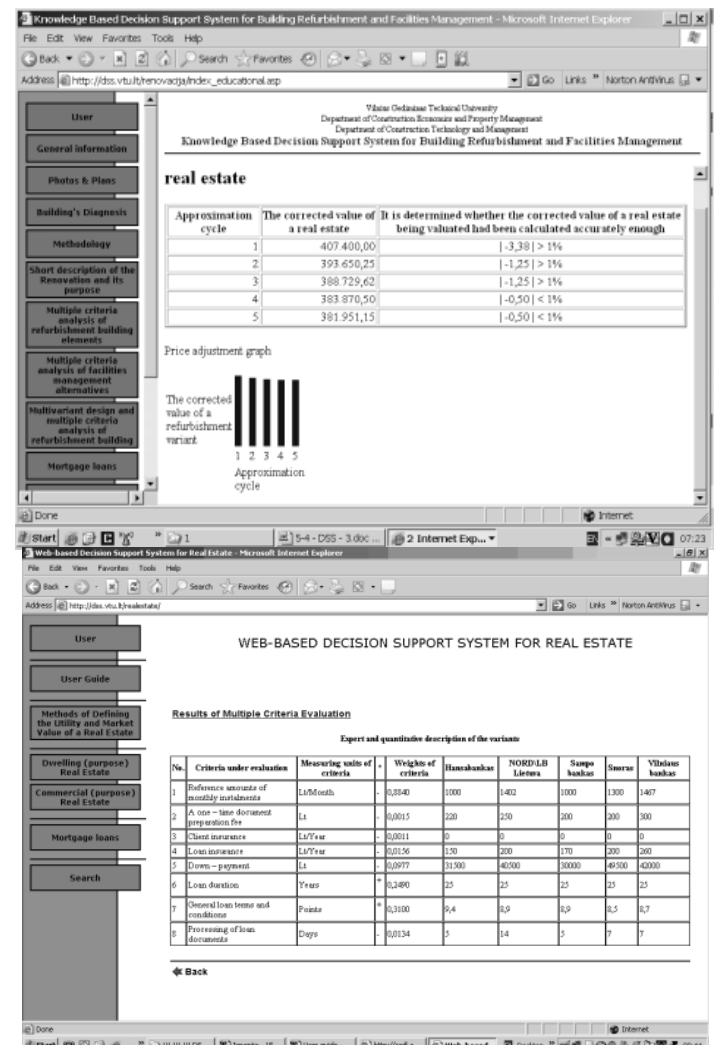

Fig. 4. Calculation of window market value (on the top) and initial data for analysis of loans offered by various banks (on the bottom))

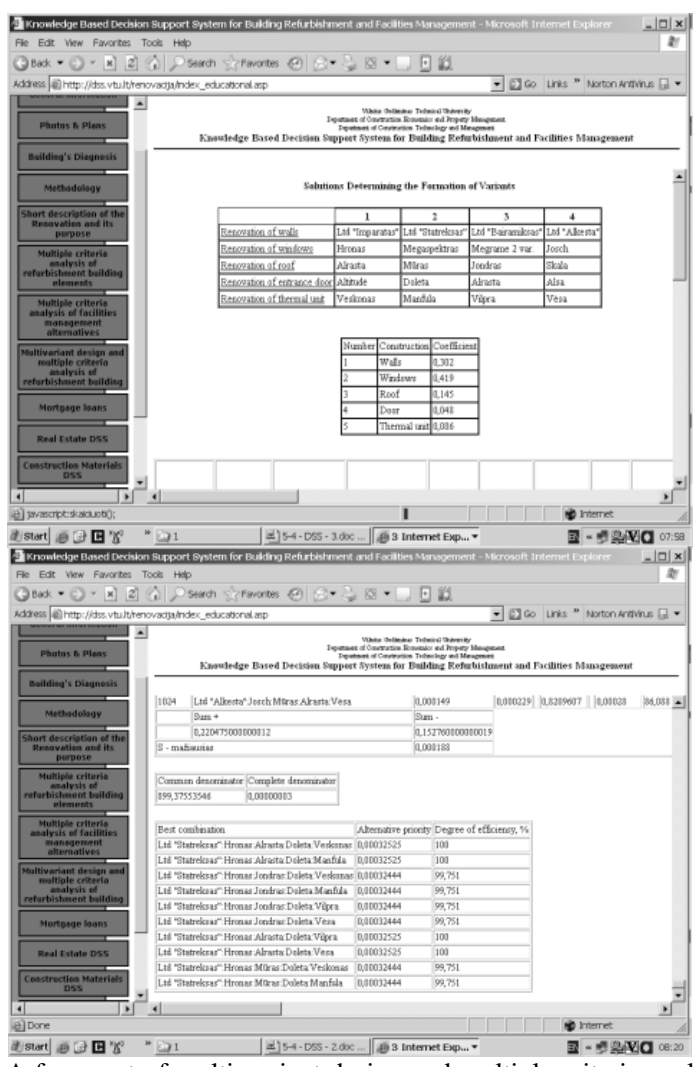

Fig. 5. A fragment of multi-variant design and multiple criteria analysis of building's refurbishment: best constructive elements of building are determined (of walls, windows, roof, etc.) (on the top); best variants for building's refurbishment are determined (on the bottom). 
There are four main categories of rules and procedures in the BR-CLS-AR Knowledge subsystem (BR-KS):

1) Formation of alternatives for the elements of a renovated building. This set of rules forms possible alternatives for the elements (e.g. windows, walls and etc.) of a renovated building.

2) Formation of the criteria describing the generated alternatives. This category consists of rule sets for formation of the system of criteria that describe the generated alternatives and provides values and weights of these criteria.

3) Development of suggestions with what suppliers to use and for what reasons further negotiation should be carried out. With the help of a BR-DSS having determined the sequence of priority, the degree of utility and market value of the elements of a renovated building, the rules in a knowledge subsystem suggests what suppliers to use and for what reasons further negotiations should be carried out. The main goal of this set of rules is to establish the most rational suppliers on the basis of the following factors: the amount of money the student is willing to pay for the elements (e.g. windows, walls and etc.) of a renovated building; the cost of the alternatives; the priority, utility degree and market value of the elements of a renovated building; the reliability of the suppliers based on their past performance with their students;

4) Composition of comprehensively reasoned negotiation e-mail for each of the selected suppliers. By using information inherited from previous BR-DSS calculations and predefined rules and procedures, the knowledge subsystem composes a negotiation e-mail for each of the selected suppliers, where it reasonably suggests that the price of a product should be decreased or a product of better quality should be sold for the offered price. The e-mail includes references to the calculations performed by BR-CLS-AR.

The above functions are performed according to the description of a building's renovation requirements and the constraints, as well as knowledge and data that are contained in the knowledge subsystem's rules and the knowledge base. Having a significant number of the above rules one can then acquire quite an advanced and complete diagnosis of the analysed situation.

Knowledge used by BR-KS is of at an expert's level and comprises of cause and effect relations that are triggered by experts' experiences participating in the creation of the BR-KS. By revealing non-formal knowledge, BR-KS allows the solving of the afore-mentioned tasks without detailed analysis of the situation.

Devices in the Device Subsystem measure internal microclimate parameters (illumination, volume flow, air velocity, air temperature, relative humidity, dew point temperature, vibration impulse amplitudes (see Fig. 6, top)) and house allergens, e.g. house dust mites, dermatophagoides pteronysinus allergen, etc. The data is passed on to the Decision Support and the Knowledge subsystems. Let us analyze the internal volume flow and relative humidity as an example. Insufficient speed of the internal volume flow determines the lack of oxygen. As a result, internal hygiene conditions are worse, flowers wither and people feel unwell and their productivity decreases. Dry air in premises causes nasal mucous to dry and creates discomfort, thus productivity and good moods decrease. The discomfort may be removed by pipetting oil into the nose. Quite a few people encounter this problem. Other microclimate parameters may be described in a similar way.

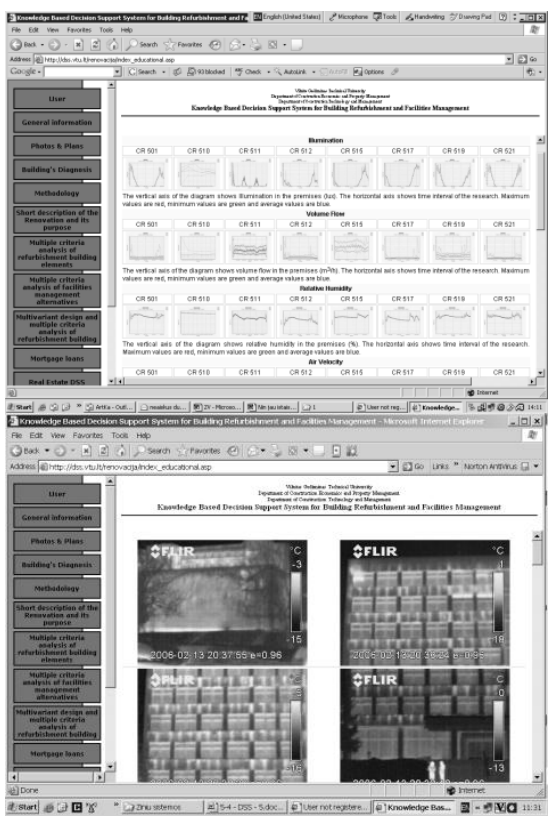

Fig. 6. Charts of internal microclimate parameters measured by devices (top) and results of termography (bottom).

The concentration of house dust mites (\%) strongly depends on the temperature of premises and humidity. When air temperature in premises is $20-25 \mathrm{C}^{\circ}$, the concentration of house dust mites is $100 \%$. When the temperature is lower (by 10 degrees) the concentration of house dust mites decreases by $40 \%$. When humidity in premises is $60-70 \%$, the concentration of house dust mites is $80 \%$. When humidity is $50 \%$, the concentration of dust mites decreases four times and makes up $20 \%$. It is clear that allergic people feel bad due to temperature and humidity fluctuations in premises, i.e. when the concentration of house dust mites increases. Mites cause allergic reactions and make people feel worse. Data about internal microclimate parameters and house allergens measured by devices are passed on to the Decision Support and Knowledge subsystems. These subsystems then use the data in further calculations.

\section{B. Mankind and Virtual and Augmented Reality. Augmented Reality Subsystem:}

The basis for virtual reality is such faculty of human mind as imagination, fantasy [5]. The concept of "imagination" is equally used in science, in art and to define common sense. Imagination may mean "realistic dreams", fantasies, day-dreaming and so on. Psychology "understands imagination as a psychological process involved in generation of new images (...) making use of transformations and recombination of a person's experiences" [6]. Anatole France (1844-1924), a French writer and Nobel laureate in literature, was fond of analysing dreams: it is wise to maintain a taste for dreaming, dreams are what makes the world a more interesting and meaningful place; if we should destroy all the dreams and visions of men, the earth would lose its form and colours, and we should all sleep in a dull 
stupidity.

André Maurois (1885-1967) once said that everything that is in agreement with our personal desires seems true; everything that is not puts us in a rage. Two men looked out from prison bars, one saw mud, the other stars. Michel de Montaigne (1533-1592), a French philosopher, wrote that a man is not hurt so much by what happens, as by his opinion of what happens.

Marcus Aurelius (121-180) said: Put from you the belief that "I have been wronged", and with it will go the feeling. Reject your sense of injury, and the injury itself disappears. Chesterton (1874-1936) believed that until we see the background of darkness, we cannot admire the light as a single and created thing. As soon as we have seen that darkness, all light is lightening, sudden, blinding, and divine. Booth Tarkington (1869-1946) said that he found he could take the loss of his eyesight, just as a man can take anything else. "If I lost all five of my senses, I know I could live on inside my mind. For it is in the mind we see and in the mind we live, whether we know it or not."

The world has seen many philosophers, writers and artists speaking on religion and virtual reality. Such themes as heaven and hell have been absolute favourites. Jesus has proclaimed that the Kingdom of Heaven is within you, just like the Kingdom of Hell. Do not fear God, fear yourself. You make your own success and you create your own misfortunes. In your own soul lives both heaven and hell (Maréchal, 1750-1803). The mind is its own place, and in itself can make a heaven of hell, a hell of heaven (Milton, 1608-1674). Other texts also dwelled on a connection between religion and virtual reality. The history of philosophy, of the sciences, and of religion all show that opinions can spread en masse, but the ones that always prevail are those that are more easily grasped, i.e., are most conformable and comfortable to the human mind in its common condition (Goethe, 1749-1832). A thousand reasons to worry, a thousand reasons for anxiety, oppress day after day the fool, but not the wise man (Narayana, a Supreme God in Hinduism). I can remember the days when people talked about the conflict between science and religion. But no more. The newest of all sciences-psychiatry-is teaching what Jesus taught. Why? Because psychiatrists realise that prayer and a strong religious faith will banish the worries, the anxieties, the strains and fears that cause more than half of all our ills (Carnegie 2009). According to the definition of the Stoics, wisdom is nothing else than to be governed by reason, and on the contrary Folly, to be given up to the will of our passions, that the life of man might not be altogether disconsolate and hard to away with, of how much more passion than reason has Jupiter composed us (Erasmus of Rotterdam, 1469-1536).

It has been established that the reality of dreams is akin to "second reality", the product of art. Gayle Delaney, an American psychologist, argues that dreams can be likened to poetry. The only way to understand them is to catch the metaphor (Begley, 1988). The poet presents the imagination with images from life and human characters and situations, sets them all in motion and leaves it to the beholder to let these images take his thoughts as far as his mental powers will permit. This is why he is able to engage men of the most differing capabilities, indeed fools and sages together. The philosopher, on the other hand, presents not life itself but the finished thoughts which he has abstracted from it and then demands that the reader should think precisely as, and precisely as far as, he himself thinks. That is why his public is so small (Arthur Schopenhauer, 1788-1860).

Every work of art, through its effect on human mind, raises "emotions from opposed senses" that cause "an explosion and discharge of nervous energy. It is in that transformation of the emotions, in that explosive reaction in which it causes the discharge of the emotions, that it causes the catharsis of the aesthetic reaction" [7].

Ancient philosophers noticed ages ago that different people had very different notions of the world. A sage's and a fool's attitudes to life were analysed as an example. Confucius (551-479 BC), a famous Chinese thinker whose teachings largely affected Chinese, Japanese, Korean and Vietnamese civilisations, cultures, philosophy and societies, said that for one word a man is often deemed to be wise, and for one word is often deemed to be foolish. Oscar Wilde (1854-1900), an Irish-born English playwright, poet and novelist, believed that the fatal errors of life are not due to man's being unreasonable. An unreasonable moment may be one's finest moment. They are due to man's being logical. Epicurus (341-270 BC), an atheist and materialist Greek philosopher, said that among other sins, a stupid man still has this one: he always starts a new life. Seneca (1 BC - AD 65) believed that a wise man is content with his lot, but a fool suffers the burden of dissatisfaction with his lot.

A number of academics and practicians in the world [8]-[12] analyzed the Augmented Reality Subsystem in building refurbishment.

Malkawi and Srinivasan [8] present an interactive speech and gesture recognition-based, immersive Augmented Reality (AR) model designed to visualize and interact with buildings and their thermal environments. Malkawi and Srinivasan [8] introduce a Human-Building Interaction (HBI) model that allows for the efficient exploration of Computational Fluid Dynamics (CFD) data sets in real time. This model includes four components: wireless sensor data, CFD analysis, Human-Computer Interaction (HCI), and AR visualization. The sensor data component tracks temperature and velocity changes that occur within a room and updates the boundary conditions for simulation. The CFD analysis component performs simulation with the new boundary conditions, and the post-processed data are exported as Virtual Reality Modeling Language (VRML) models. The HCI component consists of a library of gesture recognition tasks. These tasks update and process data for the AR visualization component. The AR visualization component aids in tracking the student's movement in real time and poses graphical information onto the Head-Mounted Device (HMD), allowing the student to visualize CFD data sets that are superimposed on to the actual scene [8].

Developed by Netherlands Architecture Institute (NAI) in partnership with IN10 Communicatie and Layar, Sara is the world's first augmented reality architecture application. Students of the technology simply hold up their smartphone to see photos, video, 3D models, scale models and other details about buildings currently in situ as well as those from the past and any planned for the future. Although it's still under construction, those with the app can view a 3D model 
of how the finished building will look. SARA also allows students to add their own information about any building or map tours of their favourite architecture. The technology was launched on December 2009 on the Layar platform and will be downloadable from the Apple App Store and Android Market beginning next month. The world's first building to appear in three dimensions on the smartphone via augmented reality is the eye-catching Market Hall which is currently under construction in Rotterdam 's Blaak area. Within the next 5 years, SARA is expected to have evolved into a complete national architecture guide [9].

Building energy performance simulation tools such as EnergyPlus, Ecotect, and eQuest are widely used to model energy performance of existing buildings and assess retrofit alternatives. Nevertheless, predictions from simulations typically deviate from actual measurements. Monitoring actual performance and measuring deviations from simulated data in $3 \mathrm{D}$ can help improve simulation accuracy through model calibrations, and in turn facilitate identification of energy performance problem. To do that, Ham and Golparvar-Fard [10] presents Energy Performance Augmented Reality (EPAR) modeling that leverages collections of unordered digital and thermal imagery, in addition to computational fluid dynamics (CFD) models. First, users collect large numbers of digital and thermal imagery from the building under inspection using a single thermal camera. Through an image-based reconstruction pipeline, actual 3D spatio-thermal models are automatically generated and are superimposed with expected building energy performance models generated using CFD analysis through a user-driven process. The outcomes are EPAR models which visualize actual and expected models in a common 3D environment. Within the EPAR models, actual measurements and simulated results can be systematically compared and analyzed. The method is validated on typical residential and instructional buildings. The results demonstrate that EPAR models facilitate calibration of building energy performance models and support detection and analysis of building performance deviations [10].

Modeling the energy performance of existing buildings enables quick identification and reporting of potential areas for building retrofit. Ham and Golparvar-Fard [11] present a new computer vision-based method for automated 3D energy performance modeling of existing buildings using thermal and digital imagery captured by a single thermal camera. By automatically superimposing the 3D building and thermal point cloud models, 3D spatio-thermal models are formed, which enable the users to visualize, query, and analyze temperatures at the level of $3 \mathrm{D}$ points. The underlying algorithms for generating and visualizing the 3D spatio-thermal models and the 3D-registered digital and thermal images are presented in detail. The proposed method is validated for several interior and exterior locations of a typical residential building and an instructional facility. The experimental results show that inexpensive digital and thermal imagery can be converted into ubiquitous reporters of the actual energy performance of existing buildings. The proposed method expedites the modeling process and has the potential to be used as a rapid and robust building diagnostic tool [11].
Malkawi and Srinivasan [12] present an interactive speech and gesture recognition-based, immersive Augmented Reality (AR) model designed to visualize and interact with buildings and their thermal environments. The paper introduces a Human-Building Interaction (HBI) model that allows for the efficient exploration of Computational Fluid Dynamics (CFD) data sets in real time. This model includes four components: wireless sensor data, CFD analysis, Human-Computer Interaction (HCI), and AR visualization. The sensor data component tracks temperature and velocity changes that occur within a room and updates the boundary conditions for simulation. The CFD analysis component performs simulation with the new boundary conditions, and the post-processed data are exported as Virtual Reality Modeling Language (VRML) models. The HCI component consists of a library of gesture recognition tasks. These tasks update and process data for the AR visualization component. The AR visualization component aids in tracking the user's movement in real time and poses graphical information onto the Head-Mounted Device (HMD), allowing the user to visualize CFD data sets that are superimposed on to the actual scene [12].

Any student with a Google account may access Google Maps at https://maps.google.com/. The site's feature My Places lets you personalise its maps with your information. Use the Placemarks tool to mark a location defined by specific coordinates in a map (e.g. to mark a building). Each placemark may have a unique title and may be linked to additional information, such as URLs, photos, HTML code, etc. Our titles refer to a building's address or a company that uses the building for its business. The additional information we provide is a link to the initial data matrix with the building's properties for refurbishment multiple criteria analysis (see Fig. 1- Fig. 6) and the building's photo. Google's Street View technology lets you take a virtual tour and explore the building's environment.

The Augmented Reality Subsystem offers real-time additional information about a piece of property (see Fig. 1Fig. 6). All property details in the databases are linked to the Google Maps service. The digital map is a convenient tool to display the pieces of property of interest to students and make intuitive choices of a property for further analysis. Once a student has selected the property of interest, the Computer Learning Subsystem opens. A student equipped with GPS coordinates and a palmtop may retrieve information about the object in which the student is at present, and compare it with other alternatives pinned in the digital map.

Google Maps tool "My places" is used to pin in a map the address of each piece of property with a marker. Each marker shows some extra information about the property such as its name, address, image, and a link to the multiple criteria analysis system that compares alternative variants of the properties marked in the map.

A mobile device with Android OS and the Maps application offers access to the map in Google Maps. An active GPS receiver in the mobile device pins the user's actual location on the map. Thus any nearby alternative variants of real estate objects are shown in the map with some extra information about them. Street View, a service by Google Maps, offers a possibility to take a virtual tour to check out what is in the vicinity of a piece of property. 


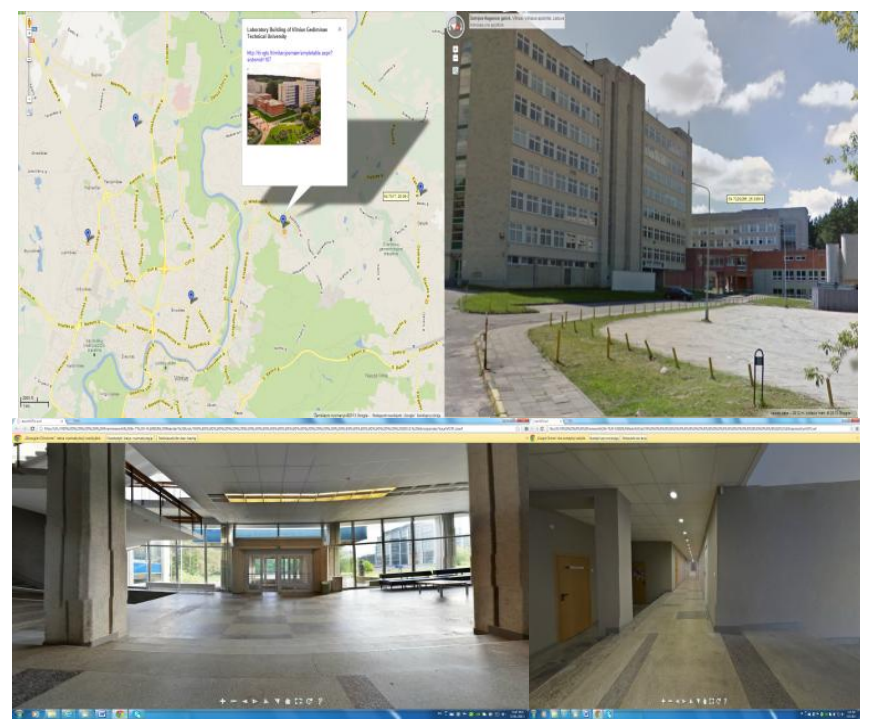

Fig. 7. Links to the multiple criteria analysis matrix that compares the alternatives have been created with the Google Maps tools; a Google Street View image of the location is shown alongside and virtual tour.

Using the Google Maps mapping tool, the location of each alternative described in the initial-data table for the multiple criteria analysis is marked on the map. Each property is pined on the city's map (blue markers on the map). The details (a link to the multiple criteria analysis system, the property's image, a link to Google Street View) of a property you are interested in can be viewed by clicking on its marker.

\section{CONCLUSION}

In order to design and realize an efficient building refurbishment, it is necessary to carry out exhaustive investigations of all the solutions that form it, i.e. planimetric and volumetric changes, the elimination of building deterioration and obsolescence, the improvement of architectural and aesthetic appearance and indoor environmental quality, etc. The efficiency level of the considered building's refurbishment depends on a great many factors, including: cost of refurbishment, annual fuel economy after refurbishment, tentative pay-back time, harmfulness to health of the materials used, aesthetics, maintenance properties, functionality, comfort, sound insulation and longevity, etc. The presented Building's Refurbishment Computer Learning System with Augmented Reality (BR-CLS-AR) enables one to form up to 100,000 alternative versions. This system allows one to determine the strongest and weakest points of each building's refurbishment project and its constituent parts. Calculations are made to find out by what degree one version is better than another and reasons, as to why this is so, are disclosed. Other BR-CLS-AR functions include creating and maintaining student's personalized objectives, preferences, and evaluation criteria; participation of various students in joint determination of criteria (criteria system, values and weights) defining building refurbishment; provide device-based data about indoor microclimates and allergens causing allergy in buildings, etc.

\section{ACKNOWLEDGMENT}

The authors thank for the help of E. Mitrofanov and R. Janovic who improve virtual tour.

\section{REFERENCES}

[1] A. Kaklauskas, E. K. Zavadskas, and S. Raslanas. Multivariant design and multiple criteria analysis of building refurbishments. Energy and Buildings, vol. 37, no. 4, pp. 361-372, 2005.

[2] A. Kaklauskas, E. K. Zavadskas, V. Trinkunas. A multiple criteria decision support on-line system for construction. Engineering Applications of Artificial Intelligence, Volume 20, issue 2, March 2007, Pages 163-175.

[3] A. Kaklauskas, Многоцелевая селектоновация технологических решений возведения сельскохозяйственных производственных зданий: дис. ... канд. техн. наук: технология и организация строительства. Днепропетровский инженерно-строительный институт; руководитель. Днепропетровск, 1990. 162 с.

[4] A. Kaklauskas. Multiple Criteria Decision Support of Building Life Cycle. Research Report Presented for Habilitation. Technika, Vilnius (60 pp). 1999.

[5] В. Даль, Explanatory Dictionary of the Russian Language (The modern spelling of words), Moscow, 1998.

[6] А. Л. Гостев, Shaped area of man, Moscow, А. Л. Указ. соч, pp. 26-27, 1992.

[7] Катарсис, Aesthetics: Dictionary, Moscow, pp. 140-141, 1989.

[8] A. M. Malkawi and R. S. Srinivasan, "A new paradigm for Human-Building Interaction: the use of CFD and Augmented Reality," Automation in Construction, vol. 14, issue 1, pp. 71-84, Jan. 2005.

[9] Sara. (2010). World's First Augmented Reality Architecture Application. $\quad$ [Online]. Available:
Ans http://freshome.com/2010/01/19/world\%E2\%80\%99s-first-augmented -reality-architecture-application-sara/

[10] Y. Ham and M Golparvar-Fard, "EPAR: Energy Performance Augmented Reality models for identification of building energy performance deviations between actual measurements and simulation results," Energy and Buildings, vol. 63, pp. 15-28, 2013.

[11] Y. Ham and M. Golparvar-Fard, "An automated vision-based method for rapid 3D energy performance modeling of existing buildings using thermal and digital imagery," Advanced Engineering Informatics, vol. 27, issue 3, August 2013, pp. 395-409.

[12] A. M. Malkawi and R. S. Srinivasan, "A new paradigm for Human-Building Interaction: the use of CFD and augmented reality," Automation in Construction, vol. 14, issue 1, pp. 71-84, 2005.

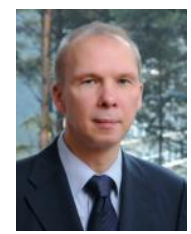

Artūras Kaklauskas is a professor and the head of the Department of Construction Economics and Property Management, Director of the Institute of Internet and Intelligent Technologies, Member of the Lithuanian Academy of Sciences and Member of the VGTU Council. $\mathrm{He}$ has participated in more than 40 projects in EU, African and Asian countries. He with collaborators developed more than 30 intelligent and biometric systems.

Vilnius Gediminas Technical University offers the distance learning Master's degree programme Property Management (since 1999), the Master's degree programme Construction Economics (since 2000), the Master's degree programme Internet Technologies and Real Estate Business (since 2003), and the Master's degree programme Intelligent Built Environment (since 2003)—all introduced by Arturas Kaklauskas.

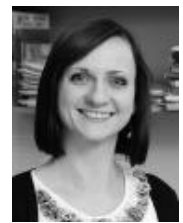

Ieva Jackute is a $\mathrm{PhD}$ student in the Department of Construction Technology and Management at Vilnius Gediminas Technical University, Vilnius, Lithuania. Research interests: computer learning systems, biometric technologies, stress management, labour productivity Ieva Jackute is a PhD student in Technology Sciences, Civil Engineering.

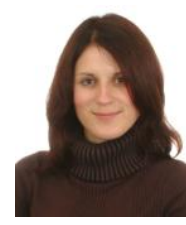

Lina Bartkiene is a PhD student in the Department of Construction Economics and Property Management at Vilnius Gediminas Technical University. Research interests: job performance, organizational effectiveness, stress management, safe and healthy work environment. Lina Bartkiene is a $\mathrm{PhD}$ student in Social Sciences, Management. 